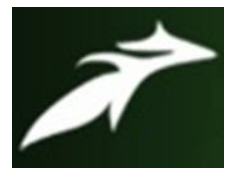

Suruchi Malik et al, International Journal of Advances in Agricultural Science and Technology,

Vol.8 Issue.9, September-2021, pg. 15-22

ISSN: 2348-1358

Impact Factor: 6.057

NAAS Rating: 3.77

\title{
BIO-SUSTAINABLE PRACTICES FOR IMPROVING SOIL HEALTH INDEX
}

\author{
Suruchi Malik ${ }^{1}$; Anil Kanaujia ${ }^{2}$ \\ ${ }^{1}$ Microbiologist, suruchi.malik@arfmail.in \\ ${ }^{2}$ Head R\&D, ank@arfmail.in \\ Research \& Development Center, Ayurvet Research Foundation, Sonepat, Haryana \\ DOI: 10.47856/ijaast.2021.v08i9.003
}

\begin{abstract}
As the anthropogenic activities are increasing day by day, the environmental pollution has also been rising. The continuous disposal and improper treatment of domestic, industrial, and agricultural wastes is highly toxic and has emerged as a serious pollution threat which is jeopardizing the environment \& human health. Soil contamination is referred to as the accumulation in the soil of persistent harmful substances, chemical compounds, radioactive wastes, salts, or pathogens that have a negative impact on biological systems. Bioremediation is a waste management technique that includes the use of living organisms to eradicate or neutralize pollutants from a contaminated site. Other processes use plants, earthworms and biochar to attenuate the toxicity of contaminants.
\end{abstract}

Keywords: Anthropogenic activities; soil contamination; bioremediation; neutralize pollutants; biochar.

\section{Introduction}

Soils are the critical ecosystem service providers for the sustenance of humanity, the material composed of five ingredients - minerals, soil organic matter, living organisms, gas, and water. They are the primary provider of nutrients and water for much of the plant life on earth. They prevent floods by transferring water slowly to streams and groundwater; filter and remediate pollutants (Brian A. Needelman, 2013).

Soil provide habitat for a vast diversity of life but unfortunately many human activities are degrading and polluting it (Brian A. Needelman, 2013).Soil contamination is referred to as the accumulation in the soil of persistent harmful substances, chemical compounds, radioactive wastes, salts, or pathogens that have a negative impact on biological systems. As such, the increased levels of toxic compounds in the soil, mainly due to heavy metals, pesticides and petroleum derivatives, affect the balance of ecosystems and human health (Israel Gonçalves Sales da Silva, et al, 2020). Mainly urban and industrial aerosols, combustion of fuels, liquid and solid from animals and human beings, mining wastes, industrial and agricultural chemicals etc. are contributing heavy metal pollution (M.A.Ashraf et al, 2014). Pesticides may exert harmful effects to microorganisms, as a result of which plant growth may be affected. Pesticides which are not rapidly decomposed may create such problems. Accumulation is residues of pesticides in higher concentrations are toxic. Pesticides persistence in soil and movement into water streams may also lead to their entry into foods and create health hazards (M.A.Ashraf et al, 2014).

Micro-organisms are well known for their ability to break down a huge range of organic compounds and absorb inorganic substances (R.Philp, 2015). Biological organisms are used to remove or neutralize an environmental pollutant by metabolic process. The "biological" organisms include microscopic organisms, such as fungi, algae and bacteria, and the "remediation" - treating the situation (I.Sharma, 2020). 


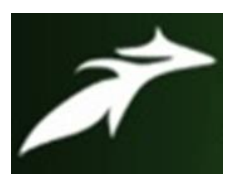

Suruchi Malik et al, International Journal of Advances in Agricultural Science and Technology,

Vol.8 Issue.9, September-2021, pg. 15-22

ISSN: 2348-1358

Impact Factor: 6.057

NAAS Rating: 3.77

There are various processes that help to remediate the contaminated soil:

The bioremediation approaches to clean up environmental pollutants are considered as emerging and sustainable methods. It is based on an integrated approach employing microbial communities such as actinomycetes, bacteria, fungi, and earthworms (P. Singh et al, 2020).

Biochar amendment mitigates soil contamination by immobilizing heavy metals and organic pollutants. Soilincorporated biochar stabilizes these pollutants and reduce their bioavailability through enhanced sorption and chemical precipitation.

Vermiremediation is the process that includes the degradation of soil contaminants through the interactions between earthworms and microorganisms.

\section{Soil Pollution \& Major Contaminants}

Soil pollution is defined as the build-up in soils of persistent toxic compounds, chemicals, salts, radioactive materials, or disease causing agents (M.A.Ashraf et al, 2014).

It has an adverse impact on food security in two ways -it can reduce crop yields due to toxic levels of contaminants, and crops grown in polluted soils are unsafe for consumption by animals and humans. It can lead to the emergence of new pests and diseases by changing the balance of ecosystems and causing the disappearance of predators or competing species that regulate their biomass. It also contributes to the spreading of antimicrobial resistant bacteria and genes, limiting humanity's ability to cope with pathogens (UNEP monthly newsletter, DEC 2020). The major contaminants are as follows:

\subsection{Heavy Metals}

Although heavy metals are naturally present in the soil, geologic and anthropogenic activities increase the concentration of these elements to amounts that are harmful to both plants and animals. Some of these activities include mining and smelting of metals, burning of fossil fuels, use of fertilizers and pesticides in agriculture, production of batteries and other metal products in industries, sewage sludge, and municipal waste disposal (G.U.Chibuike and S.C.Obiora, 2014).

\subsection{Organic Pollutants, Including Hazardous Pesticides}

Organic (carbon-based) pollutants include pesticides. Those that were once released into air or water will end up in soils, with the exception of those that are deposited at the bottom of oceans. Among organic pollutants some are referred to as 'POPs,' or persistent organic pollutants, which do not break down quickly in the environment (In-Depth Report, 2013). This has led to higher concentration of these pesticides in vegetation, in animal flesh and milk (M.A.Ashraf et al, 2014).

\section{Bioremediation}

Bioremediation is a waste management technique that includes the use of living organisms to eradicate or neutralize pollutants from a contaminated site (I.Sharma, 2020). The process involves biotransformation and biodegradation by transforming contaminants to non-hazardous or less hazardous chemicals.. Biotransformation is any alteration of the molecule or structure of a compound by micro-organisms. Biodegradation is the breaking down of organic or bioaccumulation and biotransformation of inorganic compounds into environmental friendly compounds (Singh R et al, 2014).

Microbial remediation uses multiple metabolic pathways responsible for enzyme production (S.Jaiswal, P. Shukla, 2020). As bioremediation can be effective only where environmental conditions permit microbial growth and action, its application often involves the management of ecological factors to allow microbial growth and degradation to continue at a faster rate (R.Prashad, E.Aranda, 2018). It involves the production of energy in a redox reaction within microbial cells. These reactions include respiration and other biological functions needed for cell maintenance and reproduction (Godleads Omokhagbor Adams et al, 2015). 


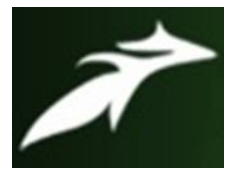

Suruchi Malik et al, International Journal of Advances in Agricultural Science and Technology, Vol.8 Issue.9, September-2021, pg. 15-22

ISSN: 2348-1358

Impact Factor: 6.057

NAAS Rating: 3.77

Bioremediation points out environmental decontamination of pollutants by microbiological processes whether in situ or ex situ. In situ bioremediation (bioventing, biosparging, and bioaugmentation) decontaminates without removal of soil from the site and ex situ (land farming, biopiling, composting, bioreactors, and electrodialysis) treat the unearth soil at the site (Bhawna Tyagi, Naveen Kumar, 2020). It utilizes the abilities of micro-organisms for degradation of toxic pollutants (Shilpa K, 2020). They are ideally suited to the task of contaminant destruction because they possess enzymes that allow them to use environmental contaminants as food (The national academics of sciences engineering medicines, 1993) \& convert them into $\mathrm{CO}_{2}, \mathrm{H}_{2} \mathrm{O}$, microbial biomass, and metabolites (by- products which are less toxic than the parent compound) (Bhawna Tyagi, Naveen Kumar, 2020).

The degradation process by the microbes depends on the favorable environmental conditions, the pollutant type which may include: agrochemicals, chlorinated compounds, dyes, greenhouse gases, heavy metals, hydrocarbons, nuclear waste, plastics, and sewage (Azubuike, C.C. et al, 2016) \& solubility, and the bioavailability of the pollutant to the microbes, therefore, the environmental conditions are controlled or manipulated to allow sufficient microbial growth and thus fast and effective biodegradation (Bhawna Tyagi, Naveen Kumar, 2020).

Microorganisms play an important role on nutritional chains that are important part of the biological balance in life. Soil remediation involves the removal of the contaminated materials with the help of bacteria, fungi, algae and yeast (Gosa Girma, 2015). Microorganisms individually cannot mineralize most hazardous compounds. Complete mineralization results in a sequential degradation by a consortium of microorganisms and involves synergism and co metabolism actions. These microorganisms include: Acinetobacter, Actinobacter, Alcaligenes, Arthrobacter, Bacillus, Beijerinckia, Flavobacterium, Methylosinus, Mycobacterium, Mycococcus, Nitrosomonas, Nocardia, Penicillium, Phanerochaete, Pseudomonas, Rhizoctonia, Serratia, Trametes and Xanthobacter (Singh R et al, 2014).Most bioremediation systems are run under aerobic conditions, but running a system under anaerobic conditions may permit microbial organisms to degrade otherwise recalcitrant molecules (Ravindra Singh et al, 2014).

\subsection{Various Techniques Of Bioremediation}

According to the type of application, it is possible to classify bioremediation as an in-situ or ex-situ process. Even though the ex-situ bioremediation processes are usually costlier because of excavation and transport expenses, they can be applied to remove a greater number of contaminants under controlled conditions. On the other hand, despite the absence of excavation costs, sometimes the cost of installing the equipment on site, together with the impossibility to see and perform an effective control below the surface of contaminated area, can make in-situ bioremediation methods unfeasible (Azubuike, C.C. et al, 2016).

Hence, the remediation cost is not the element that determines the method to be applied to a given contaminated site. Instead, the main factor for determining which method of bioremediation to use is the type of the contaminant (Azubuike, C.C. et al, 2016). The various techniques of bioremediation are given in Fig. (1) 


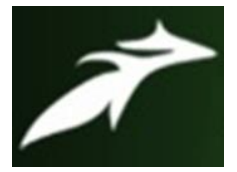

Suruchi Malik et al, International Journal of Advances in Agricultural Science and Technology, Vol.8 Issue.9, September-2021, pg. 15-22

ISSN: 2348-1358

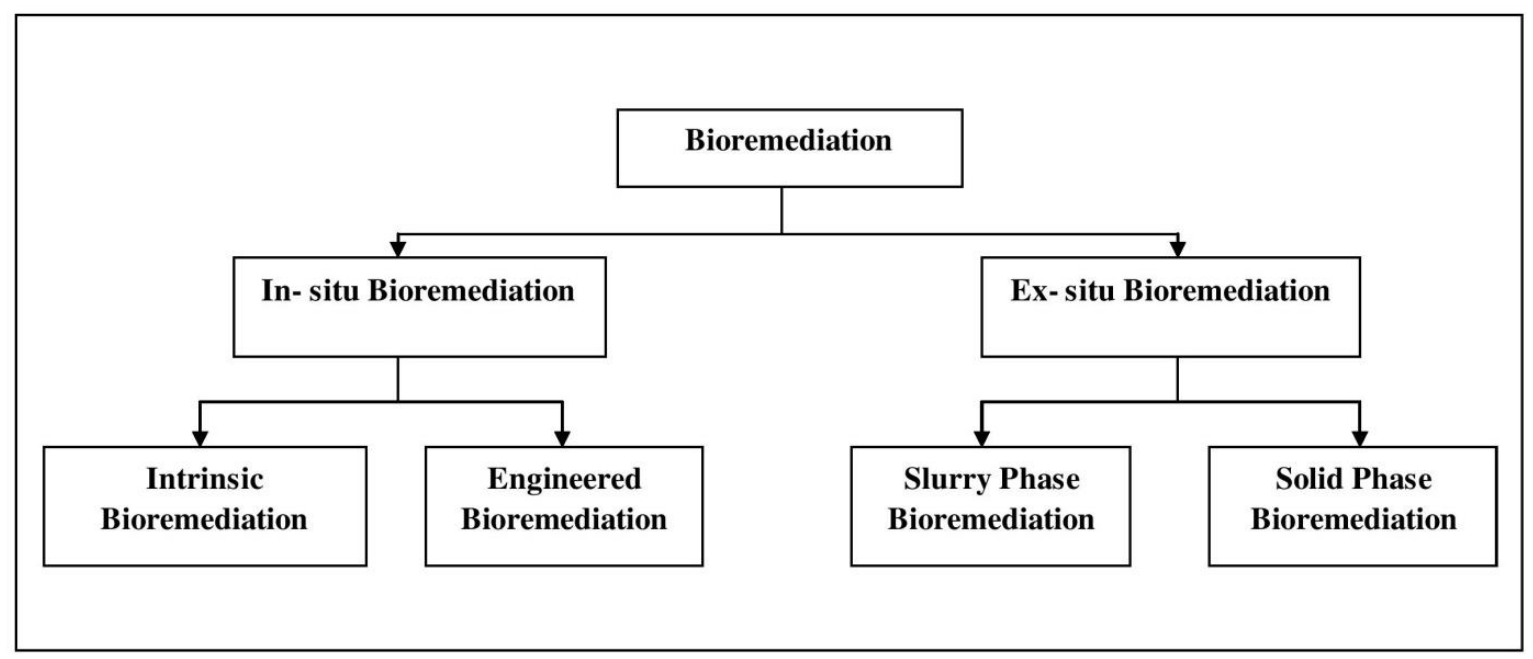

Fig. (1) Techniques of bioremediation

\subsubsection{In-Situ Bioremediation}

These techniques involve treating polluted substances at the site of pollution. It does not require any excavation; therefore, it is accompanied by little or no disturbance to soil structure (Azubuike, C.C. et al, 2016).

In situ bioremediation in the sub superficial layer is easily accessible to the environment compared to ex situ bioremediation. On site bioremediation has the potential to offer benefits, such as the total destruction of contaminants, lower risk for employees in the workplace and lower/ operational teams' costs (Maulin Pramod Shah, 2018). Most often, in- situ bioremediation is applied to the degradation of contaminants in saturated soils and groundwater. It is a superior method to cleaning contaminated environments since it is cheaper and uses harmless microbial organisms to degrade the chemicals and also a safer method in degrading harmful compounds (Gosa Girma, 2015). In-situ bioremediation can be two types. These are intrinsic bioremediation and engineered in- situ bioremediation (Gosa Girma, 2015). In-situ bioremediation techniques have been effectively used to treat chlorinated solvents, heavy metals, dyes, and hydrocarbons polluted sites (Roy M, et al, 2005).

\subsubsection{Intrinsic Bioremediation}

Alternatively called passive bioremediation or natural attenuation, intrinsic bioremediation is a natural degradation process that depends only on the metabolism of native microorganisms to destroy dangerous contaminants, using no artificial stage to enhance biodegradation activity (Kumar V et al, 2018).

In Intrinsic bioremediation the rate-controlling step is frequently the influx of oxygen. When natural oxygen supplies become depleted, the microbes may not be able to act quickly enough to contain the contamination. Lack of a sufficiently large microbial population can also limit the cleanup rate (The national academics of sciences engineering medicines, 1993).

\subsubsection{Engineered Bioremediation}

Where an impending property transfer or potential impact of contamination on the local community dictates the need for rapid pollutant removal, engineered bioremediation may be a more appropriate remedy than 


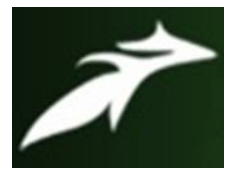

Suruchi Malik et al, International Journal of Advances in Agricultural Science and Technology, Vol.8 Issue.9, September-2021, pg. 15-22

ISSN: 2348-1358

Impact Factor: 6.057

NAAS Rating: 3.77

intrinsic bioremediation. It accelerates biodegradation reaction rates \& requires less time than intrinsic bioremediation (The national academics of sciences engineering medicines, 1993).

Some techniques in engineered bioremediation are bioventing \& biosparging

Bioventing involves controlled stimulation of the air flow via wells, providing oxygen to increase microbial activity and, consequently, enhance bioremediation (Brown L.D et al, 2017).

In Biosparging, air is introduced into the soil to promote the degradation capacity of microorganisms (Brown L.D et al, 2017) by injecting air under pressure below the water table to increase groundwater oxygen concentration.

\subsubsection{Ex- Situ Bioremediation}

This process requires excavation of contaminated soil or pumping of groundwater to facilitate microbial degradation. This technique has more disadvantages than advantages. Ex- situ bioremediation techniques involve the excavation or removal of contaminated soil from ground. Depending on the state of the contaminant to be removed, ex- situ bioremediation is classified as solid phase system and slurry phase systems (Gosa Girma, 2015).

\subsubsection{The Solid Phase Treatment}

It includes organic wastes such as leaves, animal manures and agricultural wastes and problematic wastes like domestic and industrial wastes, sewage sludge and municipal solid wastes. Solid phase soil treatment processes include land farming, soil biopiles, and composting (Gosa Girma, 2015).

Landfarming involves spreading contaminated soil into a lined bed (to prevent leaching) and periodically applying nutrients and mixing the soil to boost biological activity.

Biopiling places the contaminated soil into piles that are well aerated and nutrients are added to speed up bioremediation (Santanu Maitra, 2018). Composting is a technique that involves combining contaminated soil with nonhazardous organic amendants such as manure or agricultural wastes. The presence of these organic materials supports the development of a rich microbial population and elevated temperature characteristic of composting (Gosa Girma, 2015).

\subsubsection{Slurry Phase Bioremediation}

It is a relatively more rapid process compared to the other treatment processes. Contaminated soil is combined with water and other additives in a large tank called a bioreactor (Gosa Girma, 2015), large vessels where the contaminated material can be monitored and conditions for bioremediation can be controlled (Santanu Maitra, 2018) and mixed to keep the microorganisms, which are already present in the soil, in contact with the contaminants in the soil. Nutrients and oxygen are added and conditions in the bioreactor are controlled to create the optimum environment for the microorganisms to degrade the contaminants. When the treatment is completed, the water is removed from the solids, which are disposed of or treated further if they still contain pollutants (Gosa Girma, 2015).

In all cases, the contaminant levels are monitored to verify that bioremediation is taking place and steps are taken to ensure that contaminated material stays out of contact with the environment (Santanu Maitra, 2018). 


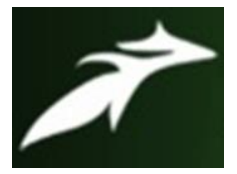

Suruchi Malik et al, International Journal of Advances in Agricultural Science and Technology, Vol.8 Issue.9, September-2021, pg. 15-22

ISSN: 2348-1358

Impact Factor: 6.057

NAAS Rating: 3.77

\section{Other Soil Remediation Techniques}

Processes other than Bioremediation to debilitate the toxicity of soil use plants, earthworms and biochar. These include Phytoremediation, Biochar-Facilitated Soil Remediation \& Vermiremediation.

\subsection{Phytoremediation}

Phytoremediation refers to the use of plants in polluted sites to promote biological, biochemical, physical, microbiological and chemical interactions to attenuate the toxicity of contaminants (Godheja J et al, 2019). Plants react to the presence of soil contaminants in many ways, namely, by accumulating them, indicating their presence, and / or extruding them out to the surface. As autotrophs, plants store pollutants in their vegetative areas and aid in the removal of undesirable content from their environment. A number of plant types have been investigated that are commonly and efficiently used for phytoremediation purposes. More than 400 plant species worldwide have been identified that have the ability to extract heavy metals from the soil. Many plant species have been explored to filter out those capable of accumulating heavy metals. Among the most researched are Thlaspi sp., Arabidopsis sp. and Sedum alfredi (Godheja J et al, 2019).

\subsection{Biochar-Facilitated Soil Remediation}

Biochar is charcoal prepared by pyrolytic processing (i.e., $\mathrm{O}_{2}$-absent heating at $300-700^{\circ} \mathrm{C}$ ) of residual biomass materials and used as a soil amendment in agricultural and environmental applications. As a soil amendment, biochar has a vital advantage over compost and other raw bio-materials in its high environmental recalcitrance. Biochar amendment immobilizes heavy metals and POPs in contaminated soils and reduces their bioavailability primarily through precipitation, electrostatic interaction, surface adsorption, structural sequestration, and facilitated decomposition; the decontamination efficacy varies with the biochar source, amendment rate, soil type, and pollutant species.

Biochar is capable of effectively sorbing heavy metal cations from water and immobilizing heavy metal elements in soil and therefore serves as a promising amendment for reducing the ecotoxicity of heavy-metalcontaminated soils. It does not eradicate but stabilizes heavy metals in soil, transforming the toxic elements into less soluble and less bioaccessible forms.

It may be a practical approach to mitigate soils polluted by pesticides, herbicides, antibiotics, PAHs, PCBs, petroleum hydrocarbons, and other POPs. After incorporation into contaminated soil with thorough mixing, biochar promptly interacts with organic contaminants and soil microorganisms. Organic contaminants are stabilized on the biochar surface and in pores and may be further decomposed by microbes as stimulated by biochar amendment (M.Guo et al, 2020).

\subsection{Vermiremediation}

Vermiremediation has been described as the use of earthworms for the removal of contaminants from soil. Earthworms are known to burrow through the soil, mixing it in their guts and consequently, they are capable of changing the physicochemical and biological properties of the soil, such as nutrient availability, aeration, soil structure and, hence, the activity of soil microbial communities. In addition, earthworms can increase the interaction between soil microbial communities and contaminants, thus facilitating the biodegradation of the target contaminants. Some studies have investigated the interaction between earthworms and metal contaminants, but vermiremediation is more commonly used for organic contaminants. Indeed, organic contaminants such as herbicides, PCBs, PAHs or, in general, petroleum-derived hydrocarbons have been successfully remediated through vermiremediation using a variety of earthworm species. A particularly 


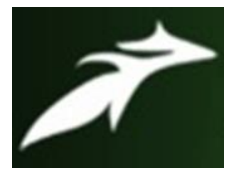

Suruchi Malik et al, International Journal of Advances in Agricultural Science and Technology, Vol.8 Issue.9, September-2021, pg. 15-22

ISSN: 2348-1358

Impact Factor: 6.057

NAAS Rating: 3.77

interesting earthworm species, Eisenia fetida, has been used for vermiremediation purposes, as well as bioindicator of metal ecotoxicity in soil (R.G. Lacalle et al, 2020).

\section{Conclusion}

Soil contamination is referred to as the accumulation in the soil of persistent harmful substances, chemical compounds, radioactive wastes, salts, or pathogens that have a negative impact on biological systems. As such, the increased levels of toxic compounds in the soil, mainly due to heavy metals, pesticides and petroleum derivatives, affect the balance of ecosystems and human health.

Bioremediation is a waste management technique that includes the use of living organisms to eradicate or neutralize pollutants from a contaminated site. The process involves biotransformation and biodegradation by transforming contaminants to non-hazardous or less hazardous chemicals. The degradation process by the microbes depends on the favorable environmental conditions, the pollutant type which may include: agrochemicals, chlorinated compounds, dyes, greenhouse gases, heavy metals, hydrocarbons, nuclear waste, plastics, and sewage \& solubility, and the bioavailability of the pollutant to the microbes, therefore, the environmental conditions are controlled or manipulated to allow sufficient microbial growth and thus fast and effective biodegradation.

Various other processes that help to remediate the contaminated soil include phytoremediation, the use of plants in polluted sites to promote biological, biochemical, physical, microbiological and chemical interactions to attenuate the toxicity of contaminants; Biochar may be a practical approach to mitigate soils polluted by pesticides, herbicides, antibiotics, PAHs, PCBs, petroleum hydrocarbons, and other POPs. After incorporation into contaminated soil with thorough mixing, biochar promptly interacts with organic contaminants and soil microorganisms; Vermiremediation describes the use of earthworms species Eisenia fetida for the removal of contaminants from soil and as bioindicator of metal ecotoxicity in soil.

\section{References}

1) Azubuike, C.C.; Chikere, C.B.; Okpokwasili, G.C., 2016, Bioremediation techniques-classification based on site of application: Principles, advantages, limitations and prospects. World J. Microbiol. Biotechnol, 32(11).

2) Bhawna Tyagi, Naveen Kumar, 2020, Bioremediation: Principles and Application in Environmental Management, Toxicity, Mechanisms of Contaminants Degradation, Detoxification and Challenges, Elsevier.

3) Brian A. Needelman, What Are Soils?, 2013, Nature Education Knowledge, 4(3):2.

4) Brown, L.D.; Cologgi, D.L.; Gee, K.F.; Ulrich, A.C., 2017, Bioremediation of Oil Spills on Land; Elsevier Inc, Amsterdam, the Netherlands.

5) Godheja, J; Modi, D.R.; Kolla, V.; Pereira, A.M.; Bajpai, R.; Mishra, M.; Sharma, S.V.; Sinha, K.; Shekhar, S.K., 2019, Environmental remediation: Microbial and nonmicrobial prospects. In Microbial Interventions in Agriculture and Environment; Springer: Singapore,; Volume 1, pp. 379-409.

6) Godleads Omokhagbor Adams, Prekeyi Tawari Fufeyin , Samson Eruke Okoro, Igelenyah Ehinomen , 2015, Bioremediation, Biostimulation and Bioaugmention: A Review, International Journal of Environmental Bioremediation \& Biodegradation, Vol. 3, No. 1, 28-39.

7) Gosa Girma, 2015, Microbial Bioremediation of some Heavy Metals in Soils: An updated review, Journal of Resources Development and Management, Vol.10.

8) G. U. Chibuike and S. C. Obiora, 2014, Heavy Metal Polluted Soils: Effect on Plants and Bioremediation Methods, Hindawi Publishing Corporation Applied and Environmental Soil Science, Article ID 752708.

9) In-Depth Report, 2013, Soil Contamination: Impacts on Human Health, Science for Environment Policy, Issue 5.

10) In Situ Bioremediation, When does it work? 1993, The national academics of sciences engineering medicines.

11) I. Sharma, 2020, Bioremediation techniques for polluted environment: Concept, Advantages, limitations, and prospects, Trace Metals in the Environment - New Approaches and Recent Advances. 


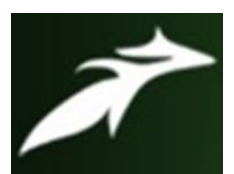

Suruchi Malik et al, International Journal of Advances in Agricultural Science and Technology, Vol.8 Issue.9, September-2021, pg. 15-22

ISSN: 2348-1358

Impact Factor: 6.057

NAAS Rating: 3.77

12) Israel Gonçalves Sales da Silva, Fabíola Carolina Gomes de Almeida , Nathália Maria Padilha da Rocha e Silva, Alessandro Alberto Casazza , Attilio Converti and Leonie Asfora Sarubbo, 2020, Soil Bioremediation: Overview of Technologies and Trends, Energies, V-13.

13) Kumar, V., Shahi, S.K., Singh, S., 2018, Bioremediation: An eco-sustainable approach for restoration of contaminated sites. In Microbial Bio prospecting for Sustainable Development; Springer: Singapore, 115-136.

14) M.A.Ashraf, M.J.Maah, I.Yusoff, 2014, Soil Contamination, Risk assessment \& remediation, Environmental Risk Assessment of Soil Contamination.

15) Maulin Pramod Shah, In-situ Bioremediation Modern Perspective, Research \& Reviews: Journal of Ecology and Environmental Sciences, 2018, V-6, Issue 1(50-51).

16) M.Guo, W. Song and J.Tian, 2020, Biochar-Facilitated Soil Remediation: Mechanisms and Efficacy Variations, Frontiers in Environmental Science, V-8.

17) O. Surriya, S.S.Saleem, K.Waqar and A.G.Kazi, 2014, Phytoremediation of Soils: Prospects and Challenges, Atta-ur-Rahman School of Applied Biosciences, National University of Sciences and Technology

18) P. Singh, V. Kumar Singh, R. Singh, A. Borthakur, S. Madhav, A. Ahamad, A. Kumar, D.B.Pal, D.Tiwary, P.K.Mishra, 2020, Bioremediation: a sustainable approach for management of environmental contaminants, Science direct, Abatement of Environmental Pollutants, 1-23.

19) Ravindra Singh, Pushpendra Singh, Rajesh Sharma, 2014, Microorganism as a tool of bioremediation technology for cleaning environment: A review, International Academy of Ecology and Environmental Sciences, V- 4(1): 1-6

20) R.G. Lacalle, J.M. Becerril, C.Garbisu, 2020, Biological Methods of Polluted Soil Remediation for an Effective Economically-Optimal Recovery of Soil Health and Ecosystem Services, Journal of Environmental Science and Public Health.

21) Roy M, Giri AK, Dutta S, Mukherjee P., 2005, Integrated phytobial remediation for sustainable management of arsenic in soil and water. Environment International; V-75:180-198.

22) R.Philp, 2015, Bioremediation: the pollution solution? Microbiology society.

23) R.Prashad, E.Aranda, 2018, Approaches in Bioremediation The New Era of Environmental Microbiology and Nano biotechnology, Springer.

24) Santanu Maitra, 2018, Ex situ bioremediation - an overview, Research Journal of Life sciences, Bioinformatics, Pharmaceuticals \& Chemical Sciences, V-4(6):.422-437

25) Singh R, Singh P, Sharma R., 2014, Microorganism as a tool of bioremediation technology for cleaning environment: A review. International Academy of Ecology and Environmental Science.;V-4(1):1-6

26) S.Jaiswal, P. Shukla, 2020, Alternative Strategies for Microbial Remediation of Pollutants via Synthetic Biology, Frontiers in microbiology, V-11.

27) Shilpa K, 2020, Bioremediation: Principle, Need, Advantages and Limitations | Environment, Environmental pollution.

28) Soil pollution a risk to our health and food security, DEC 2020, UNEP monthly newsletter.

\section{A Brief Author Biography}

Ms. Suruchi Malik- An enthusiastic and fervid professional in microbiology. Completed Post-graduation in Microbiology from CCS University, Meerut in 2020 \& PG diploma in food safety \& quality management from IGNOU, Delhi. Have 1.5 years of experience of analytical testing in chemical \& microbiological analysis in Food, Feed, Water, Milk \& Milk products. Involved in Research \& development activities for food safety \& sustainable development.

Dr. Anil Kanaujia -Skilled Scientist with 25+ years of experience in natural product chemistry and medicinal chemistry based new drug discovery research, process chemistry, research on food safety, isolation \& characterization of molecules from medicinal plants using Flash chromatography, 1H, 13C and 2D NMR spectroscopic techniques; commercialization of standardized herbal extracts, standardization of polyherbal formulations, analytical research \& method development and validation using HPLC-PDA, HPTLC, AAS, UV VIS spectrophotometer etc. techniques. Currently working with the AYURVET RESEARCH FOUNDATION, Sonepat, Haryana, as Head- R\&D, managing and providing the guidance on innovative research projects to the team of professionals. Credited with 14 patents (10 US, 1 Chinese, 3 Indian), published 27 research articles in peer reviewed international and national journals. 